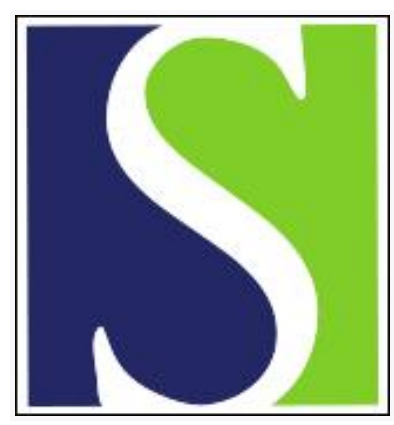

Scand J Work Environ Health 2002;28(4):278-284

https://doi.org/10.5271/sjweh.676

Issue date: Aug 2002

Occupational dust exposure and the risk of laryngeal cancer in Turkey

by Elci OC, Akpinar-Elci M, Blair A, Dosemeci M

Affiliation: National Institute for Occupational Safety and Health, Division of Respiratory Diseases Studies, Field Studies Branch, MS 2800, 1095 Willowdale Road, Morgantown, WV 26505, United States. oae3@cdc.gov

Refers to the following text of the Journal: 2001;27(4):233-239

Key terms: case-control study; case-referent study; cotton; epidemiology; laryngeal cancer; larynx; occupational dust exposure; risk; silica; Turkey; work

This article in PubMed: www.ncbi.nlm.nih.gov/pubmed/12199430 


\title{
Occupational dust exposure and the risk of laryngeal cancer in Turkey
}

\author{
by Omur Cinar Elci, MD, ${ }^{1,3}$ Muge Akpinar-Elci, MD, ${ }^{2,3}$ Aaron Blair, PhD, ${ }^{1}$ Mustafa Dosemeci, PhD ${ }^{1}$
} Elci OC, Akpinar-Elci M, Blair A, Dosemeci M. Occupational dust exposure and the risk of laryngeal cancer in
Turkey. Scand J Work Environ Health 2002;28(4):278-284.

\begin{abstract}
Objectives A hospital-based case-referent study was conducted to identify occupational risk factors for laryngeal cancer. In a previous report an association was found between laryngeal cancer and occupations with potential dust exposure; a job-exposure matrix was developed to aid further evaluation of laryngeal cancer risks from five occupational dust exposures.

Methods Among 7631 cancer cases from the Okmeydani Hospital, Istanbul, between 1979 and 1984, 958 larynx cancer cases were identified among men. After exclusions, 940 laryngeal cancer cases and 1519 referents were available. A standardized questionnaire was used to obtain basic information on the patients. Seven-digit standard occupational and industrial codes were created to classify the job and industrial titles. A job-exposure matrix was developed for occupational dusts, including silica, asbestos, wood, cotton, and grain, and age-, smoking-, and alcohol-adjusted odds ratios (OR) and 95\% confidence intervals (95\% CI) were calculated to evaluate risks of laryngeal cancer.

Results An excess of laryngeal cancer occurred for workers potentially exposed to silica and cotton dust, particularly for supraglottic cancer (OR 1.8, 95\% CI 1.3-2.3, for silica and OR 1.6, 95\% CI 1.1-2.5, for cotton dust), and there was a significant dose-response relationship with silica exposure. No relationship was found between laryngeal cancer and asbestos, grain, or wood dust exposures.

Conclusion Laryngeal cancer, especially supraglottic tumors, is associated with silica and cotton dust exposures in Turkey.
\end{abstract}

Key terms case-referent study, case-control study, cotton, epidemiology, larynx, work, silica.

Laryngeal cancer is an important cancer in Turkey, with an age-standardized incidence rate of 11.5 per 100000 for men, which is almost twice that of the world rate (5.7 per 100000$)(1)$. As the second leading cancer, it has been responsible for about $7.0 \%$ of the deaths among men in Turkey $(2,3)$. Although alcohol and tobacco consumption is the most important factor in the etiology of laryngeal cancer, occupational and environmental factors also play a role (4-6). Increased risk of laryngeal cancer among those exposed to various dusts has been reported (7-9).

We conducted a hospital-based case-referent study of several cancers in Istanbul, Turkey. In a previous report, we found that the risk of laryngeal cancer was as- sociated with several occupations and that supraglottic laryngeal cancer appeared to be linked to occupations with possible occupational exposure to dust (10). To evaluate further this observation, we developed a jobexposure matrix to assess the potential risks from five occupational dust exposures.

\section{Subjects and methods}

Both the cases and referents were selected from patients admitted to the Oncology Treatment Center of the Social Security Agency Okmeydani Hospital, Istanbul,

3 Current affiliation: National Institute for Occupational Safety and Health, Division of Respiratory Diseases Studies, Morgantown, West Virginia, United States.

Reprint requests to: Dr Omur Cinar Elci, National Institute for Occupational Safety and Health, Division of Respiratory Diseases Studies, Field Studies Branch, MS2800, 1095 Willowdale Road, Morgantown, WV 26505, United States. [E-mail: oae3@cdc.gov] 
Turkey, between 1979 and 1984. The center provides cancer treatment for workers in the Marmara region, which is the northwest part of Turkey, and also to some workers from other regions. The nationwide target population of the hospitals of the Social Security Agency is limited to workers who have similar population characteristics. Each hospital serves a defined geographic area. This oncology treatment center was part of the largest hospital in the area. As a regular procedure upon admission to the hospital, regardless of their diagnosis, all patients give their informed consents and respond to a standardized questionnaire administered by trained interviewers seeking information on demography, occupational history, and tobacco and alcohol use. All the patients with a primary tumor were selected as our study population. None of these patients refused to participate in the study. Details of the data collection have been explained elsewhere (11). Among the 7631 primary cancer cases admitted to this hospital between 1979 and 1984, there were 958 laryngeal cancers.

An oncologist from the hospital reviewed the records of patients for diagnostic verification and coded them according to the classification system of the International Classification of Diseases for Oncology (ICD-O) (12). We used four-digit ICD-O codes of laryngeal cancers (ICD-O 161.0, 161.1, 161.2, 161.9) to classify tumor location. Cases with subglottic (ICD-O 161.2, $\mathrm{N}=12$ ) and unclassified (ICD-O 161.9, $\mathrm{N}=263$ ) cancers were combined for this analysis $(\mathrm{N}=275,29.3 \%)$. Glottic (ICDO $161.0, \mathrm{~N}=227,24.1 \%$ ) and supraglottic (ICD-O $161.1, \mathrm{~N}=438,46.6 \%$ ) tumors were considered separately. More than $95 \%$ of the laryngeal cancer cases had a histopathologic diagnosis of squamous cell carcinoma; because of the small variability, we did not include histological subgroups in our analyses.

Workers with incomplete information on age, smoking, alcohol, job titles, industry titles, and tumor site and also the small number of women $(\mathrm{N}=7)$ were excluded, leaving 940 laryngeal cancer cases for this study. From the hospital registry, we selected all the male patients with Hodgkin's disease $(\mathrm{N}=202)$, soft tissue sarcoma $(\mathrm{N}=130)$, and cancers of nonmelanoma skin $(\mathrm{N}=657)$, testis $(\mathrm{N}=219)$, bone $(\mathrm{N}=66)$, male breast $(\mathrm{N}=34)$, and a series of noncancer subjects $(\mathrm{N}=211)$ for the reference group $(\mathrm{N}=1519)$. These cancers were selected for the reference group because they are thought not to share similar etiologic factors with laryngeal cancer. Two hundred and eleven patients with benign pathologies were also used as referents. Initially they were misdiagnosed as cancer and admitted to the Okmeydani Hospital for treatment and then re-evaluated and diagnosed with other (benign) pathologies.

We coded occupations and industries using a modification of the Standard Occupational Classification (SOC) and Standard Industrial Classification (SIC) sys- tem (13). We created special 7-digit SOC and SIC codes to evaluate occupational exposures in specific groups $(10,14)$.

With the use of the 7-digit SOC and SIC codes, jobexposure assignments were completed for common occupational dusts in Turkey, including silica, asbestos, wood, cotton, grain, and leather dust, by an industrial hygienist who had extensive experience in occupational settings in Turkey. We had only nine cases exposed to leather dust; therefore we excluded the results on leather dust exposure from this manuscript. For each occupation and industry, we assigned exposure intensity and probability levels independently on a scale of 0-3 $(0=$ no, $1=$ low, $2=$ medium, and $3=$ high exposure $)$. For the intensity assignments, the exposure intensity of the substance of interest was $1=$ lower than threshold limit value (TLV) (15), 2 = between the TLV and two times the TLV (15), 3 = greater than two times the TLV (15). For probability, we assigned the exposure probability of the workers for a substance of interest as $1=$ lower than $25 \%, 2=$ between 25 and $75 \%, 3=$ greater than $75 \%$ in given occupational and industrial categories.

We then combined occupational and industrial exposure scores, where appropriate, using the following algorithms. For some situations, exposure was dependent on occupation only, and we calculated the final score by an algorithm based on the SOC (intensity = intensity $_{\mathrm{soc}} \times$ intensity $_{\mathrm{soc}}$; and probability $=$ probability $_{\mathrm{soc}} \times$ probability $\left._{\text {soc }}\right)$. If the exposure depended on occupation and industry, the exposure score was assigned using an algorithm multiplying the SOC-based and SIC-based assignments (intensity $=$ intensity $_{\mathrm{soc}} \times$ intensity $_{\text {sic }}$; and probability $=$ probability $_{\mathrm{soc}} \times$ probability $\left._{\mathrm{sic}}\right)$. In the application of these algorithms, each person received final intensity and probability scores for each occupation and industry combination. We classified these scores as follows: no (score 0), low (score 1-2), medium (score 34), and high (score 6-9) exposure. Examples of the application of the job-exposure matrix are presented in table 1. During the exposure assignment, the case or referent status of the subjects was masked. Details of the exposure assessment procedures have been reported elsewhere (16).

To evaluate possible dose-response relationships within the exposure intensity groups and exposure probability groups, we used a linear trend analysis; to estimate odds ratios (OR) and 95\% confidence intervals (95\% CI) adjusted for age, smoking, and alcohol, we used the unconditional logistic regression analysis in SPSS ${ }^{\circledR}$ version 10.1. The mean age was 52.9 (SD10.3) years for the laryngeal cancer cases and 47.1 (SD 15.4) years for the referents. Although $73.9 \%$ of the cases were smokers and $24.5 \%$ regularly consumed alcohol, smoking and alcohol consumption were less common among the referents (58.6 and $13.4 \%$, respectively). The age-adjusted odds 
Table 1. Examples of the application of the job-exposure matrix. ${ }^{a}$ (SOC=Standard Occupational Classification, SIC=Standard Industrial Classification)

\begin{tabular}{lcccc}
\hline & \multicolumn{4}{c}{ Exposure } \\
\cline { 2 - 5 } Example $^{\text {b }}$ & Intensity & Origin & Score & Group \\
\hline Case A & 3 & SOC & High \\
Occupation: stone cutter (6861-029) & 2 & & $32=9$ & Medium \\
Industry: road construction (1611-012) & 2 & SOC \& SIC & $2 \times 2=4$ & \\
Case B & 2 & & & \\
Occupation: drilling operator (7518-012) & & & \\
\hline
\end{tabular}

a Based on silica exposure.

${ }^{b}$ Code of the SOC or SIC in parentheses.

Table 2. Risk of laryngeal cancer by exposure and anatomic location. ( $\mathrm{OR}=0 \mathrm{dds}$ ratio, $95 \% \mathrm{Cl}=95 \%$ confidence interval)

\begin{tabular}{|c|c|c|c|c|c|c|c|c|c|c|c|c|c|c|c|c|}
\hline \multirow[b]{2}{*}{$\begin{array}{l}\text { Exposure } \\
\text { (ever-never) }\end{array}$} & \multicolumn{4}{|c|}{ All laryngeal cancers } & \multicolumn{4}{|c|}{ Supraglottic cancer } & \multicolumn{4}{|c|}{ Glottic cancer } & \multicolumn{4}{|c|}{ Other cancers } \\
\hline & $\begin{array}{l}\text { Cases } \\
\text { (N) }\end{array}$ & $\begin{array}{l}\text { Referents } \\
\text { (N) }\end{array}$ & $\mathrm{OR}^{\mathrm{a}}$ & $95 \% \mathrm{Cl}$ & $\begin{array}{l}\text { Cases } \\
\text { (N) }\end{array}$ & $\begin{array}{l}\text { Referents } \\
\text { (N) }\end{array}$ & $\mathrm{OR}^{\mathrm{a}}$ & $95 \% \mathrm{Cl}$ & $\begin{array}{l}\text { Cases } \\
\text { (N) }\end{array}$ & $\begin{array}{l}\text { Referents } \\
\text { (N) }\end{array}$ & $\mathrm{OR}^{\mathrm{a}}$ & $95 \% \mathrm{Cl}$ & $\begin{array}{l}\text { Cases } \\
(\mathrm{N})\end{array}$ & $\begin{array}{l}\text { Referents } \\
\text { (N) }\end{array}$ & $O R^{a}$ & $95 \% \mathrm{Cl}$ \\
\hline Silica dust & 186 & 227 & 1.5 & $1.2-1.9$ & 100 & 227 & 1.8 & $1.3-2.3$ & 34 & 227 & 1.1 & $0.7-1.7$ & 52 & 227 & 1.4 & $0.9-2.0$ \\
\hline Asbestos & 150 & 250 & 1.0 & $0.8-1.3$ & 71 & 250 & 1.0 & $0.8-1.4$ & 28 & 250 & 0.8 & $0.5-1.2$ & 51 & 250 & 1.2 & $0.9-1.7$ \\
\hline Wood dust & 109 & 173 & 1.1 & $0.8-1.4$ & 55 & 173 & 1.2 & $0.9-1.7$ & 21 & 173 & 0.9 & $0.6-1.5$ & 33 & 173 & 1.2 & $0.8-1.7$ \\
\hline Cotton dust & 54 & 74 & 1.3 & $0.9-1.9$ & 30 & 74 & 1.6 & $1.1-2.5$ & 10 & 74 & 1.1 & $0.5-2.2$ & 14 & 74 & 1.2 & $0.7-2.2$ \\
\hline Grain dust & 31 & 37 & 1.3 & $0.8-2.1$ & 13 & 37 & 1.1 & $0.6-2.1$ & 5 & 37 & 0.9 & $0.4-2.4$ & 13 & 37 & 1.9 & $0.9-3.8$ \\
\hline
\end{tabular}

a Adjusted for age, smoking, and alcohol consumption.

ratio was for laryngeal cancer among the smokers and alcohol consumers were 1.7 (95\% CI 1.4-2.1) and 2.0 (95\% CI 1.6-2.6), respectively. We did not have pack · year and bottle $\cdot$ year information for up to $50 \%$ of the subjects who reported smoking or drinking alcohol. For those with pack year or bottle $\cdot$ year information, the odds ratios for laryngeal cancer did not differ for occupational exposures by the odds ratios for ever-never data. Consequently, we used ever-never data in our analyses.

\section{Results}

The evaluation of the job-exposure matrix showed that the most common exposures among the laryngeal cancer cases were silica, asbestos, and wood dust $(20 \%$, $16 \%$, and $12 \%$, respectively). Exposure to cotton dust $(6 \%)$ and grain dust (3\%) was lower than the other exposures.

Risks of laryngeal cancer by anatomic distributions from ever-never exposure are presented in table 2 . We observed an excess of laryngeal cancer among the subjects exposed to silica dust and cotton dust, particularly for supraglottic cancers (OR 1.8, 95\% CI 1.3-2.3, and
OR $1.6,95 \%$ CI 1.1-2.5, respectively). The odds ratio for "other" laryngeal cancers was elevated for grain dust, but the heterogeneity of this category made it difficult to interpret.

In table 3, we present the risks of laryngeal cancer by the anatomic location of the tumors according to the exposure intensity levels. Laryngeal cancer risk increased by silica exposure intensity levels of low, medium, and high (OR 1.4, 1.5, and 1.7, respectively) $\left(\chi_{\text {trend }}^{2}=11.5 \mathrm{P}=0.001\right)$. This dose-response relationship was the sharpest among the cases with supraglottic tumors (OR 1.4, 1.8, and 2.2, respectively) $\left(\chi_{\text {trend }}^{2}=19.3\right.$ $\mathrm{P}<0.001)$. Although the dose-response relationship between cotton dust exposure and the risk of laryngeal cancer was not statistically significant $\left(\chi_{\text {trend }}^{2}=1.9\right.$ $\mathrm{P}=0.169$ ), it was significant for supraglottic cancers, for which there was a 2.4-fold excess risk for high-level exposure $\left(\chi_{\text {trend }}^{2}=4.8 \mathrm{P}=0.028\right)$. We did not observe any dose-response relationship with asbestos, grain, or wood dust exposure.

Laryngeal cancer risks from exposure probability are presented in table 4 by anatomic location. The probability of the silica exposure and the risk of laryngeal cancer showed a dose-response relationship (OR 0.8, 1.5 , and 1.8 respectively) $\left(\chi_{\text {trend }}^{2}=12.5 \mathrm{P}<0.001\right)$. The 
Table 3. Risk of laryngeal cancer by exposure intensity levels and anatomic location. (OR=0dds ratio, $95 \% \mathrm{Cl}=95 \%$ confidence interval)

\begin{tabular}{|c|c|c|c|c|c|c|c|c|c|c|c|c|c|c|c|c|}
\hline \multirow[b]{2}{*}{ Exposure } & \multicolumn{4}{|c|}{ All laryngeal cancers } & \multicolumn{4}{|c|}{ Supraglottic cancer } & \multicolumn{4}{|c|}{ Glottic cancer } & \multicolumn{4}{|c|}{ Other cancers } \\
\hline & $\begin{array}{l}\text { Cases } \\
\text { (N) }\end{array}$ & $\begin{array}{l}\text { Referents } \\
\text { (N) }\end{array}$ & $\mathrm{OR}^{\mathrm{a}}$ & $95 \% \mathrm{Cl}$ & $\begin{array}{l}\text { Cases } \\
\text { (N) }\end{array}$ & $\begin{array}{l}\text { Referents } \\
\text { (N) }\end{array}$ & $\mathrm{OR}^{\mathrm{a}}$ & $95 \% \mathrm{Cl}$ & $\begin{array}{c}\text { Cases } \\
(\mathrm{N})\end{array}$ & $\begin{array}{l}\text { Referents } \\
\text { (N) }\end{array}$ & $\mathrm{OR}^{\mathrm{a}}$ & $95 \% \mathrm{Cl}$ & $\begin{array}{l}\text { Cases } \\
(\mathrm{N})\end{array}$ & $\begin{array}{l}\text { Referents } \\
\text { (N) }\end{array}$ & $\mathrm{OR}^{\mathrm{a}}$ & $95 \% \mathrm{Cl}$ \\
\hline \multicolumn{17}{|l|}{ Silica dust } \\
\hline Low intensity & 48 & 69 & 1.4 & $1.0-2.1$ & 22 & 69 & 1.4 & $0.9-2.4$ & 13 & 69 & 1.5 & $0.8-2.9$ & 13 & 69 & 1.3 & $0.7-2.4$ \\
\hline Medium intensity & 94 & 114 & 1.5 & $1.1-2.0$ & 51 & 114 & 1.8 & $1.2-2.6$ & 13 & 114 & 0.8 & $0.5-1.5$ & 30 & 114 & 1.6 & $1.1-2.5$ \\
\hline High intensity & 44 & 44 & 1.7 & $1.1-2.6$ & 27 & 44 & 2.2 & $1.3-3.6$ & 8 & 44 & 1.2 & $0.5-2.6$ & 9 & 44 & 1.2 & $0.5-2.4$ \\
\hline \multicolumn{17}{|l|}{ Asbestos } \\
\hline Low intensity & 45 & 84 & 0.9 & $0.6-1.3$ & 18 & 84 & 0.8 & $0.5-1.3$ & 10 & 84 & 0.8 & $0.4-1.6$ & 17 & 84 & 1.2 & $0.7-2.1$ \\
\hline Medium intensity & 93 & 129 & 1.2 & $0.9-1.6$ & 47 & 129 & 1.3 & $0.9-1.9$ & 16 & 129 & 0.9 & $0.5-1.5$ & 30 & 129 & 1.4 & $0.9-2.2$ \\
\hline High intensity & 12 & 37 & 0.6 & $0.3-1.1$ & 6 & 37 & 0.6 & $0.3-1.5$ & 2 & 37 & 0.4 & $0.1-1.6$ & 4 & 37 & 0.7 & $0.2-1.9$ \\
\hline \multicolumn{17}{|l|}{ Wood dust } \\
\hline Low intensity & 22 & 46 & 0.8 & $0.5-1.4$ & 9 & 46 & 0.8 & $0.4-1.6$ & 4 & 46 & 0.6 & $0.2-1.7$ & 9 & 46 & 1.1 & $0.5-2.4$ \\
\hline Medium intensity & 71 & 89 & 1.4 & $1.0-1.9$ & 38 & 89 & 1.6 & $1.1-2.4$ & 12 & 89 & 1.0 & $0.5-2.0$ & 21 & 89 & 1.5 & $0.9-2.5$ \\
\hline High intensity & 16 & 38 & 0.8 & $0.4-1.4$ & 8 & 38 & 0.8 & $0.4-1.8$ & 5 & 38 & 1.0 & $0.4-2.6$ & 3 & 38 & 0.5 & $0.1-1.6$ \\
\hline \multicolumn{17}{|l|}{ Cotton dust } \\
\hline Low intensity & 12 & 23 & 0.8 & $0.4-1.6$ & 6 & 23 & 0.9 & $0.3-2.2$ & 4 & 23 & 1.2 & $0.4-3.6$ & 2 & 23 & 0.5 & $0.1-2.2$ \\
\hline Medium intensity & 11 & 17 & 1.2 & $0.6-2.7$ & 4 & 17 & 1.1 & $0.4-3.3$ & 3 & 17 & 1.4 & $0.4-4.9$ & 4 & 17 & 1.6 & $0.5-4.9$ \\
\hline High intensity & 31 & 34 & 1.7 & $1.1-2.9$ & 20 & 34 & 2.4 & $1.3-4.2$ & 3 & 34 & 0.8 & $0.3-2.8$ & 8 & 34 & 1.6 & $0.7-3.6$ \\
\hline \multicolumn{17}{|l|}{ Grain dust ${ }^{b}$} \\
\hline Low intensity & 19 & 24 & 1.2 & $0.6-2.3$ & 9 & 24 & 1.2 & $0.6-2.8$ & 4 & 24 & 1.2 & $0.4-3.7$ & 6 & 24 & 1.5 & $0.6-3.6$ \\
\hline $\begin{array}{l}\text { Medium + high } \\
\text { intensity }\end{array}$ & 12 & 13 & 1.4 & $0.6-3.1$ & 4 & 13 & 0.9 & $0.3-2.8$ & 1 & 13 & 0.4 & $0.1-3.4$ & 7 & 13 & 2.8 & $1.0-7.3$ \\
\hline
\end{tabular}

a Adjusted for age, smoking, and alcohol consumption.

${ }^{b}$ The medium- and high-intensity groups were merged due to the small number of cases.

Table 4. Risk of laryngeal cancer by exposure probability levels and anatomic location. (OR=0dds ratio, $95 \% \mathrm{Cl}=95 \%$ confidence interval)

\begin{tabular}{|c|c|c|c|c|c|c|c|c|c|c|c|c|c|c|c|c|}
\hline \multirow[b]{2}{*}{ Exposure } & \multicolumn{4}{|c|}{ All laryngeal cancers } & \multicolumn{4}{|c|}{ Supraglottic cancer } & \multicolumn{4}{|c|}{ Glottic cancer } & \multicolumn{4}{|c|}{ Other cancers } \\
\hline & $\begin{array}{l}\text { Cases } \\
\text { (N) }\end{array}$ & $\begin{array}{l}\text { Referents } \\
\text { (N) }\end{array}$ & $\mathrm{OR}^{\mathrm{a}}$ & $95 \% \mathrm{Cl}$ & $\begin{array}{l}\text { Cases } \\
\text { (N) }\end{array}$ & $\begin{array}{l}\text { Referents } \\
\text { (N) }\end{array}$ & $\mathrm{OR}^{\mathrm{a}}$ & $95 \% \mathrm{Cl}$ & $\begin{array}{l}\text { Cases } \\
\text { (N) }\end{array}$ & $\begin{array}{l}\text { Referents } \\
\text { (N) }\end{array}$ & $\mathrm{OR}^{\mathrm{a}}$ & $95 \% \mathrm{Cl}$ & $\begin{array}{l}\text { Cases } \\
\text { (N) }\end{array}$ & $\begin{array}{l}\text { Referent } \\
\text { (N) }\end{array}$ & ts $0 R^{a}$ & a $95 \% \mathrm{Cl}$ \\
\hline \multicolumn{17}{|l|}{ Silica dust } \\
\hline Low probability & 19 & 37 & 0.8 & $0.5-1.5$ & 8 & 37 & 0.8 & $0.4-1.7$ & 6 & 37 & 1.0 & $0.4-2.5$ & 5 & 37 & 0.7 & $0.3-1.8$ \\
\hline Medium probability & y 83 & 101 & 1.5 & $1.1-2.0$ & 45 & 101 & 1.7 & $1.2-2.6$ & 14 & 101 & 1.0 & $0.6-1.8$ & 24 & 101 & 1.5 & $0.9-2.4$ \\
\hline $\begin{array}{l}\text { High probability } \\
\text { Asbestos }\end{array}$ & 84 & 89 & 1.8 & $1.3-2.5$ & 47 & 89 & 2.3 & $1.5-3.3$ & 14 & 89 & 1.3 & $0.7-2.3$ & 23 & 89 & 1.7 & $1.1-2.8$ \\
\hline Low probability & 121 & 176 & 1.2 & $0.9-1.5$ & 58 & 176 & 1.2 & $0.9-1.7$ & 23 & 176 & 0.9 & $0.6-1.5$ & 40 & 176 & 1.4 & $1.0-2.1$ \\
\hline Medium probability & y 20 & 51 & 0.6 & $0.4-1.1$ & 8 & 51 & 0.5 & $0.3-1.1$ & 3 & 51 & 0.4 & $0.1-1.2$ & 9 & 51 & 1.0 & $0.5-2.1$ \\
\hline High probability & 9 & 23 & 0.7 & $0.3-1.5$ & 5 & 23 & 0.8 & $0.3-2.1$ & 2 & 23 & 0.6 & $0.1-2.4$ & 2 & 23 & 0.5 & $0.1-2.1$ \\
\hline \multicolumn{17}{|l|}{ Wood dust } \\
\hline Low probability & 81 & 108 & 1.3 & $1.0-1.7$ & 41 & 108 & 1.4 & $1.0-2.1$ & 14 & 108 & 0.9 & $0.5-1.6$ & 26 & 108 & 1.4 & $0.9-2.3$ \\
\hline Medium probability & y 19 & 29 & 1.4 & $0.7-2.5$ & 9 & 29 & 1.4 & $0.7-3.1$ & 4 & 29 & 1.3 & $0.4-3.8$ & 6 & 29 & 1.4 & $0.6-3.5$ \\
\hline High probability & 9 & 36 & 0.4 & $0.2-0.9$ & 5 & 36 & 0.5 & $0.2-1.3$ & 3 & 36 & 0.6 & $0.2-2.1$ & 1 & 36 & 0.2 & $0.0-1.2$ \\
\hline \multicolumn{17}{|l|}{ Cotton dust ${ }^{\mathrm{b}}$} \\
\hline $\begin{array}{l}\text { Low probability } \\
\text { Medium + high }\end{array}$ & 53 & 74 & 1.3 & $0.9-1.9$ & 29 & 74 & 1.5 & $1.0-2.4$ & 10 & 74 & 1.1 & $0.5-2.2$ & 14 & 74 & 1.2 & $0.7-2.2$ \\
\hline probability & - & & & & - & & & & - & & & & - & & & \\
\hline \multicolumn{17}{|l|}{ Grain dust ${ }^{b}$} \\
\hline Low probability & 17 & 24 & 1.2 & $0.6-2.2$ & 7 & 24 & 1.1 & $0.4-2.5$ & 4 & 24 & 1.4 & $0.5-4.1$ & 6 & 24 & 1.6 & $0.6-4.0$ \\
\hline $\begin{array}{l}\text { Medium + high } \\
\text { probability }\end{array}$ & 14 & 13 & 1.4 & $0.7-3.2$ & 6 & 13 & 1.2 & $0.4-3.3$ & 1 & 13 & 0.4 & $0.1-2.9$ & 7 & 13 & 2.5 & $1.0-6.6$ \\
\hline
\end{tabular}

a Adjusted for age, smoking, and alcohol consumption.

${ }^{\mathrm{b}}$ Medium- and high-probability groups were merged due to small number of cases.

dose-response relationship between silica exposure and supraglottic laryngeal cancer also remained significant (OR 0.8, 1.7, and 2.3, respectively) $\left(\chi_{\text {trend }}^{2}=19.1\right.$ $\mathrm{P}<0.001)$.
To eliminate possible intensity misclassification from a low-level exposure probability group, we analyzed the risk of laryngeal cancer from silica exposure intensity levels by separating the low probability 
Table 5. Risk of supraglottic laryngeal cancer by silica intensity and probability levels. ${ }^{a}$ (OR=odds ratio, $95 \% \mathrm{Cl}=95 \%$ confidence interval)

\begin{tabular}{|c|c|c|c|c|c|c|c|c|c|c|c|c|c|c|c|c|}
\hline \multirow[b]{4}{*}{ Intensity } & \multicolumn{16}{|c|}{ Probability } \\
\hline & \multicolumn{8}{|c|}{ All laryngeal cancers } & \multicolumn{8}{|c|}{ Supraglottic } \\
\hline & \multicolumn{4}{|c|}{ Low exposure } & \multicolumn{4}{|c|}{ Medium + high exposure } & \multicolumn{4}{|c|}{ Low exposure } & \multicolumn{4}{|c|}{ Medium + high exposure } \\
\hline & $\begin{array}{l}\text { Cases } \\
(\mathrm{N})\end{array}$ & $\begin{array}{l}\text { Referents } \\
\text { (N) }\end{array}$ & OR & $95 \% \mathrm{Cl}$ & $\begin{array}{c}\text { Cases } \\
\text { (N) }\end{array}$ & $\begin{array}{l}\text { Referents } \\
\text { (N) }\end{array}$ & $\mathrm{OR}$ & $95 \% \mathrm{Cl}$ & $\begin{array}{l}\text { Cases } \\
\text { (N) }\end{array}$ & $\begin{array}{l}\text { Referents } \\
\text { (N) }\end{array}$ & $\mathrm{OR}$ & $95 \% \mathrm{Cl}$ & $\begin{array}{l}\text { Cases } \\
\text { (N) }\end{array}$ & $\begin{array}{l}\text { Referents } \\
\text { (N) }\end{array}$ & OR & $95 \% \mathrm{Cl}$ \\
\hline Low & 17 & 26 & 1.1 & $0.6-2.1$ & 31 & 43 & 1.7 & $1.0-2.7$ & 6 & 26 & 0.9 & $0.4-2.2$ & 16 & 43 & 1.9 & $1.0-3.4$ \\
\hline Medium & 2 & 11 & 0.3 & $0.1-1.3$ & 92 & 103 & 1.6 & $1.2-2.2$ & 2 & 11 & 0.6 & $0.1-2.7$ & 49 & 103 & 2.0 & $1.3-2.8$ \\
\hline High & - & & & & 44 & 44 & 1.7 & $1.1-2.6$ & - & & & & 27 & 44 & 2.2 & $1.3-3.6$ \\
\hline
\end{tabular}

group from the medium + high probability groups. An excess risk of supraglottic cancer remained for the medium + high probability groups regardless of the intensity level (table 5). There were insufficient numbers of exposed cases to perform a similar analysis for cotton dust.

\section{Discussion}

In an earlier paper we identified several occupations with possible dust exposure that appeared to increase the risk of laryngeal cancer, especially supraglottic tumors (10). In this report we evaluated the risk of laryngeal cancer for selected occupational dust exposures (ie, asbestos, silica, cotton, grain, and wood) using a jobexposure matrix specifically developed for this investigation. Supraglottic laryngeal cancer was associated with possible exposure to silica and cotton dust.

Although it is categorized as a lung carcinogen, few studies have mentioned silica exposure as a risk factor for laryngeal cancer (17). A high rate of laryngeal cancer was noted in a Mediterranean area where silica exposure is also one of the most common occupational exposures (18). Laforest et al (19) found no significant association between laryngeal cancer and silica exposure, but three other studies suggested a possible relationship between silica exposure and laryngeal cancer without examining the occupational risk in relation to the anatomic location of the tumors $(7,20,21)$. In our previous study, we found an increased risk of laryngeal cancer among extractive workers, street cleaners, and, especially, construction workers who had an excess risk of supraglottic tumors (10). They are likely to have had silica exposure. A recent study of the construction industry in the United States reported silica levels for 8to 10 -hour workday estimations up to 280 times higher than the recommended exposure limit (REL) of 0.05 $\mathrm{mg} / \mathrm{m}^{3}$ of the National Institute for Occupational Safety and Health (22). Various other occupational factors, such as diesel exhaust exposure and radioactivity, have also been reported as etiologic factors of laryngeal cancer among workers prone to silica exposure, and they can be considered as possible confounders for our results $(23,24)$.

We found no excess risk among asbestos-exposed workers. Laryngeal cancer and asbestos exposure has been evaluated in some studies. Several studies including a cohort of Quebec chrysotile workers found no association between laryngeal carcinoma and asbestos exposure (25-32). In a review it was concluded that neither the longitudinal or cross-sectional data could support asbestos as an etiologic factor for laryngeal cancer (33). Other studies, however, suggested asbestos exposure as a possible risk factor $(4,34-35)$. The difficulty of identifying and estimating asbestos exposure may have prevented us from observing a relationship between asbestos exposure and laryngeal cancer; further investigations would be helpful to clarify the role of asbestos exposure in the etiology of laryngeal cancer.

We saw some evidence of an excess risk of laryngeal cancer, particularly for supraglottic tumor, among the subjects with high-level exposure to cotton dust. In our previous report, we found an excess risk of supraglottic tumors among blue-collar textile workers exposed to cotton dust among their occupational exposures (10). The bacterial endotoxins found in cotton dust induce the release of the tumor necrosis factor (TNF- $\alpha$ ) interferon and stimulate mitogenic and macrophage activity, which play an important protective role against lung cancer among cotton workers $(37,38)$. This protective activity of endotoxins may not apply to laryngeal cancer. There was a significant increase in the number of deaths from laryngeal cancer among cotton-exposed workers in a recent cohort study (39).

We did not observe any risk of laryngeal cancer with exposure to grain and wood dusts. Few studies have evaluated the risk of laryngeal cancer for these exposures and some reported an increased or slightly elevated risk of laryngeal cancer with wood dust exposure $(40,41)$, but most of the studies did not $(4$, 
19, 35, 42). The International Agency for Research on Cancer (IARC) concluded that wood dust exposure increases the risk of paranasal and hypopharyngeal cancer, but not laryngeal carcinoma (43).

This study offered the opportunity to evaluate the role of some occupational dusts in the etiology of laryngeal cancer, but the study limitations should be considered. We had no actual monitoring data for occupational exposures and duration of exposure. Consequently the misclassification of exposure was a concern. In addition, the SOC and SIC classifications may have been biased due to age differences between the cases and referents, such that older cases were likely to have worked longer years than the referents, which may have increased the probability of occupational exposure. But further evaluation showed that there was a negligible difference between the average number of job titles among the cases and referents. A strength, however, is that the development of the job-exposure matrix was carried out by an experienced industrial hygienist familiar with the industrial settings in Turkey. Previous assessments indicate that intensity misclassification mostly occurred in the low probability of exposure groups (14). In an effort to eliminate any possible risk of intensity misclassification, we analyzed the risk of laryngeal cancer from exposure intensity by separating the low probability and medium + high probability groups (table 5). Excess remained for supraglottic tumors, as well as all for laryngeal cancers, in the medium + high probability silica-exposed groups; this finding supports a possible relationship between silica exposure and laryngeal cancer. The lack of a fullset of population-based referents could also have been a limitation. However, cancer referents have been effectively used in other studies (44). Our analyses using the noncancer patients for referents did not show any significant differences from the odds ratios based on cancer referents. Although we had some information on alcohol and tobacco use, the level of consumption was not available for about $50 \%$ of the subjects. We controlled logistic models by ever-never use of tobacco and alcohol and observed a slight decease in the odds ratios. Comparing the smoking ever-never and alcohol ever-never groups independently showed that the odds ratio for silica exposure was slightly higher among the smokers than among the nonsmokers and among the alcohol users than among the nonalcohol users. According to these further evaluations, our results should be interpreted cautiously, given the possibility of residual confounding. However, previous reports have found few examples of confounding by tobacco use and occupational risk of cancer $(45,46)$.

The major strength of our study was the large number of larynx cancer cases from a developing country; this large number provided the opportunity to eval- uate occupational risks by the anatomic location of tumor. Occupational exposures in Turkey may be greater than in developed countries, where most previous studies on occupation and laryngeal cancer have been conducted. Modified 7-digit SOC and SIC codes gave us a chance to examine occupations and industries intensely.

In summary, we found an excess risk of laryngeal cancer among workers exposed to silica and cotton dust in a large study in Turkey. Our analyses by the anatomic location of the cancers showed a particularly strong association with supraglottic larynx cancer. We observed a significant dose-response relationship for supraglottic cancer with silica exposure intensity and probability. Future studies should evaluate the biomechanism of occupational exposures and their relationship to cancer in different anatomic regions of the larynx.

\section{Acknowledgments}

The authors wish to thank Dr Michael D Attfield for his review and comments on the statistical analyses and Molly Picket-Harner for her effort in editing the language of this report.

\section{References}

1. Parkin DM, Pisani P, Ferlay J. Global cancer statistics. CA Cancer J Clin 1999;49:33-64.

2. Firat D. Cancer mortality in Turkey and in the world 19801981. Ankara: Turkish Association for Cancer Research and Control, 1983.

3. Parkin DM, Pisani P, Ferlay J. Estimates of the worldwide incidence of 25 major cancers in 1990. Int J Cancer 1999;80:827-41.

4. Austin DF, Reynolds PI. Laryngeal Cancer. In: Schottenfeld D, Fraumeni JF Jr, editors. Cancer epidemiology and prevention. 2nd ed. New York (NY): Oxford University Press, 1996:619-36.

5. Cattaruzza MS, Maisonneuve P, Boyle P. Epidemiology of laryngeal cancer. Eur J Cancer B Oral Oncol 1996;32:293305.

6. Van Cauwenberge P, Dhooge I, Ingels K. Epidemiology and etiological factors of laryngeal cancer. Acta Otorhinolaryngol Belg 1992;46:99-102.

7. Bravo MP, Espinosa J, Calero JR. Occupational risk factors for cancer of the larynx in Spain. Neoplasma 1990;37:47781.

8. Maier H, Tisch M. Epidemiology of laryngeal cancer: results of the Heidelberg case-control study. Acta Otolaryngol Suppl 1997;527:160-64.

9. Zemla B, Day N, Swiatnicka J, Banasik R. Larynx cancer risk factors. Neoplasma 1987;34:223-33.

10. Elci OC, Dosemeci M, Blair A. Occupation and the risk of laryngeal cancer in Turkey. Scand J Work Environ Health 
2001;27:233-39.

11. Dosemeci M, Gokmen I, Unsal M, Hayes RB, Blair A. Tobacco, alcohol use, and risks of laryngeal and lung cancer by sub site and histologic type in Turkey. Cancer Causes Control 1997;8:729-37.

12. World Health Organization (WHO). International classification of diseases for oncology. 2nd ed. Geneva: WHO, 1990.

13. US Government Printing Office. US Department of Commerce standard occupational classification manual. Washington (DC): US Government Printing Office, 1980.

14. Dosemeci M, Cocco P, Gomez M, Stewart PA, Heineman EF. Effects of three features of a job-exposure matrix on risk estimates. Epidemiology 1994;5:124-7.

15. American Conference of Governmental Industrial Hygienists (ACGIH). Threshold limit values for chemical substances and physical agents and biologic exposure indices. Cincinnati (OH): ACGIH, 2002.

16. Gomez MR, Cocco P, Dosemeci M, Stewart PA. Occupational exposure to chlorinated aliphatic hydrocarbons: job exposure matrix. Am J Ind Med 1994;26:171-83.

17. International Agency for Research on Cancer (IARC). Silica, some silicates, coal dust and para-aramid fibrils. Lyon: IARC, 1997. IARC monographs on the evaluation of the carcinogenic risks of chemicals to humans, vol 68 .

18. Gonzalez CA, Agudo A. Occupational cancer in Spain. Environ Health Perspect 1999;107 suppl:273-7.

19. Laforest L, Luce D, Goldberg P, Begin D, Gerin M, Demers PA, et al. Laryngeal and hypopharyngeal cancers and occupational exposure to formaldehyde and various dusts: a case-control study in France. Occup Environ Med 2000;57:767-73.

20. Haguenoer JM, Cordier S, Morel C, Lefebvre JL, Hemon D. Occupational risk factors for upper respiratory tract and upper digestive tract cancers. Br J Ind Med 1990;47:380-3.

21. Puntoni R, Goldsmith DF, Valerio F, Vercelli M, Bonassi S, Di Giorgio F, et al. A cohort study of workers employed in a refractory brick plant. Tumori 1988;74:27-33.

22. Linch KD. Respirable concrete dust-silicosis hazard in the construction industry. Appl Occup Environ Hyg 2002;17: 209-21.

23. Goldberg M, Goldberg P, Leclerc A, Chastang JF, Marne MJ, Dubourdieu D. A 10-year incidence survey of respiratory cancer and a case-control study within a cohort of nickel mining and refining workers in New Caledonia. Cancer Causes Control 1994;5:15-25.

24. Tirmarche M. Radon and cancer risk: epidemiological studies after occupational or domestic exposure. Rev Epidemiol Sante Publique 1995;43:451-60.

25. Newhouse ML, Gregory MM, Shannon H. Etiology of carcinoma of the larynx. In: International Agency for Reseach on Cancer (IARC). IARC scientific publication, no 37. Lyon: IARC, 1980;687-95.

26. Marchand JL, Luce D, Leclerc A, Goldberg P, Orlowski E, Bugel I, et al. Laryngeal and hypopharyngeal cancer and occupational exposure to asbestos and man-made vitreous fibers: results of a case-control study. Am J Ind Med 2000;37: 581-9.

27. Botta M, Magnani C, Terracini B, Bertolone GP, Castagneto $\mathrm{B}$, Cocito $\mathrm{V}$, et al. Mortality from respiratory and digestive cancers among asbestos cement workers in Italy. Cancer Detect Prev 1991;15:445-7.
28. Browne K, Gee JB. Asbestos exposure and laryngeal cancer. Ann Occup Hyg 2000;44:239-50.

29. Chan CK, Gee JB. Asbestos exposure and laryngeal cancer: an analysis of the epidemiologic evidence. J Occup Med 1988;30:23-7.

30. Muscat JE, Wynder EL. Tobacco, alcohol, asbestos, and occupational risk factors for laryngeal cancer. Cancer 1992;69:2244-51.

31. McDonald JC, Liddell FD, Gibbs GW, Eyssen GE, McDonald AD. Dust exposure and mortality in chrysotile mining, 1910-75. Br J Ind Med 1980;37:11-24.

32. McDonald JC, McDonald AD. Chrysotile, tremolite and carcinogenicity. Ann Occup Hyg 1997;41:699-705.

33. Parnes SM. Asbestos and cancer of the larynx: is there a relationship? Laryngoscope 1990;100:254-61.

34. Goodman M, Morgan RW, Ray R, Malloy CD, Zhao K. Cancer in asbestos-exposed occupational cohorts: a metaanalysis. Cancer Causes Control 1999;10:453-65.

35. Gustavsson P, Jakobsson R, Johansson H, Lewin F, Norell S, Rutkvist LE. Occupational exposures and squamous cell carcinoma of the oral cavity, pharynx, larynx, and oesophagus: a case-control study in Sweden. Occup Environ Med 1998; 55:393-400.

36. Smith AH, Handley MA, Wood R. Epidemiological evidence indicates asbestos causes laryngeal cancer. J Occup Med 1990;32:499-507.

37. Enterline PE, Sykora JL, Keleti G, Lange JH. Endotoxins, cotton dust, and cancer. Lancet 1985;2:934-35.

38. Hodgson JT, Jones RD. Mortality of workers in the British cotton industry in 1968-1984. Scand J Work Environ Health 1990;16:113-20.

39. Szeszenia-Dabrowska N, Wilczynska U, Strzelecka A, Sobala W. Mortality in the cotton industry workers: results of a cohort study. Int J Occup Med Environ Health 1999;12:14358.

40. Maier H, Gewelke U, Dietz A, Heller WD. Risk factors of cancer of the larynx: results of the Heidelberg case-control study. Otolaryngol Head Neck Surg 1992;107:577-82.

41. Vaughan TL, Davis S. Wood dust exposure and squamous cell cancers of the upper respiratory tract. Am J Epidemiol 1991;133:560-4.

42. Demers PA, Kogevinas M, Boffetta P, Leclerc A, Luce D, Gerin M, et al. Wood dust and sino-nasal cancer: pooled reanalysis of twelve case-control studies. Am J Ind Med 1995;28:151-66.

43. International Agency for Research on Cancer (IARC). Wood dust, and formaldehyde. Lyon: IARC, 1995. IARC monographs on the evaluation of the carcinogenic risks of chemicals to humans, no 62 .

44. Siemiatycki J. Case-control design and fieldwork methods. In: Siemiatycki J, editor. Risk factors for cancer in the workplace. Boco Raton (FL): CRC Press, 1991:31-33.

45. Blair A, Steenland K, Shy C, O'Berg M, Halperin W, Thomas T. Control of smoking in occupational epidemiologic studies: methods and needs. Am J Ind Med 1988;1:3-4.

46. Blair A, Hoar SK, Walrath J. Comparison of crude and smoking-adjusted standardized mortality ratios. J Occup Med $1985 ; 12: 881-84$.

Received for publication: 5 October 2001 